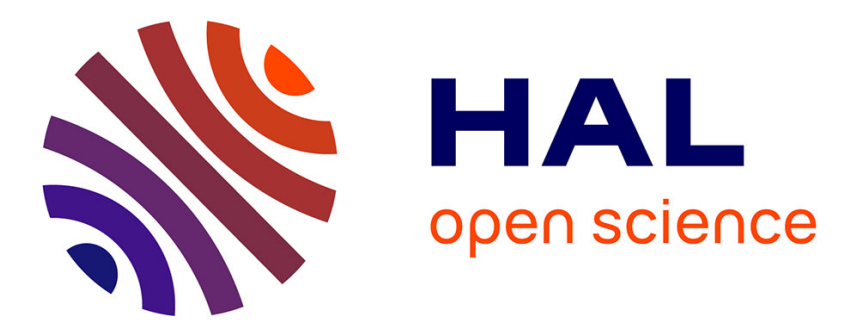

\title{
Evaluation of heading performance with vibrotactile guidance: The benefits of information-movement coupling compared with spatial language
}

\author{
Elise Faugloire, Laure Lejeune
}

\section{- To cite this version:}

Elise Faugloire, Laure Lejeune. Evaluation of heading performance with vibrotactile guidance: The benefits of information-movement coupling compared with spatial language. Journal of Experimental Psychology: Applied, 2014, 20 (4), pp.397-410. 10.1037/xap0000032 . hal-01985236

HAL Id: hal-01985236

https://hal-normandie-univ.archives-ouvertes.fr/hal-01985236

Submitted on 17 Jan 2019

HAL is a multi-disciplinary open access archive for the deposit and dissemination of scientific research documents, whether they are published or not. The documents may come from teaching and research institutions in France or abroad, or from public or private research centers.
L'archive ouverte pluridisciplinaire HAL, est destinée au dépôt et à la diffusion de documents scientifiques de niveau recherche, publiés ou non, émanant des établissements d'enseignement et de recherche français ou étrangers, des laboratoires publics ou privés. 


\section{Journal of Experimental Psychology: Applied}

Evaluation of Heading Performance With Vibrotactile Guidance: The Benefits of Information-Movement Coupling Compared With Spatial Language

Elise Faugloire and Laure Lejeune

http://dx.doi.org/10.1037/xap0000032

(C) 2015 American Psychological Association

http://www.apa.org/pubs/journals/xap/

\section{CITATION}

Faugloire, E., \& Lejeune, L. (2014). Evaluation of heading performance with vibrotactile guidance: the benefits of information-movement coupling compared with spatial language. Journal of Experimental Psychology: Applied, 20(4), 397-410. doi: 10.1037/xap0000032

This is the author version of the article: it may not exactly replicate the final version published in the APA journal. It is not the copy of record. The published version of the article is available at: http://psycnet.apa.org/journals/xap/20/4/397/ 



\title{
Evaluation of Heading Performance With Vibrotactile Guidance: The Benefits of Information-Movement Coupling Compared With Spatial Language
}

\author{
Elise Faugloire and Laure Lejeune \\ Normandie Université and UNICAEN
}

\begin{abstract}
This study quantified the effectiveness of tactile guidance in indicating a direction to turn to and measured its benefits compared to spatial language. The device (CAYLAR), which was composed of 8 vibrators, specified the requested direction by a vibration at the corresponding location around the waist. Twelve participants were tested in normal light and in total darkness with three guidance conditions: spatial language, a long tactile rhythm ( $1 \mathrm{~s} \mathrm{on} / 4 \mathrm{~s}$ off vibrations) providing a single stimulation before movement, and a short rhythm (200 ms on/200 ms off vibrations) allowing information-movement coupling during body rotation. We measured response time, heading error, and asked participants to rate task easiness, intuitiveness and perceived accuracy for each guidance mode. Accuracy was higher and participants' ratings were more positive with the short tactile mode than with the two other modes. Compared to spatial language, tactile guidance, regardless of the vibration rhythm, also allowed faster responses and did not impair accuracy in the absence of vision. These findings quantitatively demonstrate that tactile guidance is particularly effective when it is reciprocally related to movement. We discuss implications of the benefits of perception-action coupling for the design of tactile navigation devices.
\end{abstract}

Keywords: navigation assistance systems, tactile device, vibration rhythm, spatial information, heading direction

Being able to orient oneself in the environment depends widely upon the perceptual information available to guide turning movements and control heading (the direction one is facing). In some circumstances (e.g., unknown route, visual impairment, hostile environments), additional information is necessary to locate objects or places and navigate effectively. The vast majority of devices designed to provide that information such as global positioning based systems (GPS) involve visual and auditory modalities, but in the past decade, a growing number of studies have investigated the use of the sense of touch, and more specifically vibrotactile stimulation, to provide directional information.

This increasing interest in vibrotactile displays can be explained by both recent technological improvements (e.g., miniaturization of electronic components, improvements in vibrators, development of global positioning systems) and the fact that communicating information through the skin offers multiple benefits (e.g., Jones \& Sarter, 2008). For example,

Elise Faugloire and Laure Lejeune, Unité de Formation et de Recherche en Sciences et Techniques des Activités Physiques et Sportives, CesamS EA 4260, Normandie Université and Université de Caen (UNICAEN).

This research was supported in part by the French Direction Générale de l'Armement Grant REI 2008.34.0030. We thank the CAYLAR company for designing and making the vibrotactile display. We also thank Patrick Fenouil for developing the custom software used in the present study, and Marie-Charlotte Lepelley, Colas Levaufre and Clémence Richard for their help in setting up the apparatus and running the participants.

Correspondence concerning this article should be addressed to Elise Faugloire, UFR STAPS, UNICAEN, 2 Boulevard du Maréchal Juin, F-14032 Caen Cedex, France. E-mail: elise.faugloire@unicaen.fr tactile cues may provide invaluable assistance when access to visual and auditory information is limited or impossible, such as in noisy, dark, or smoke-filled environments, and for people with hearing or visual impairment. Even in more common situations, tactile displays offer the great advantage of leaving the eyes, ears and hands free to perform other tasks (e.g., van Erp \& Self, 2008), such as picking up visual and auditory information in the nearby surroundings (rather than listening to spatial cues or continuously monitoring a display screen), conversing with others, and using hands for other activities (rather than holding, for example, a visual display).

Applications of tactile guidance are thus widely varied, ranging from assisting a pedestrian, a pilot, or a diver in reaching a location, to guiding perceptually impaired people for obstacle avoidance, and remotely leading players over large sports fields (e.g., Castle \& Dobbins, 2004; van Erp, Saturday, \& Jansen, 2006). The promising functional opportunities offered by vibrotactile devices have inspired a growing number of scientific and technical studies. Several tactile devices for navigation assistance have been proposed, such as the Personal Tactile Navigator (e.g., van Erp, Spapé, \& Van Veen, 2003), the Wearable tactile navigation system (e.g., Zelek, \& Holbein, 2008), the Feelspace belt (Nagel, Carl, Kringe, Märtin, \& König, 2005), the ActiveBelt (Tsukada \& Yasumura, 2004), and the Tactabelt (Lindeman, Sibert, Mendez-Mendez, Patil, \& Phifer, 2005). Tactile guidance has also already been investigated to assist navigation for various populations including blind people (Ghiani, Leporini, \& Paternò, 2009; Marston, Loomis, Klatzky, \& Golledge, 2007), deaf people (Borg, Rönnberg, \& Neovius, 2001), older people (Grierson, Zelek, \& Carnahan, 2009), people with dementia (Grierson, Zelek, Lam, Black, \& Carnahan, 2011), soldiers (e.g., Elliott, van Erp, Redden, \& Duistermaat, 2010), and ordinary pedestrians (Nagel et al., 2005; Pielot, Poppinga, Heuten, \& Boll, 2011; Tsukada \& Yasumura, 2004; van Erp, van 
Veen, Jansen, \& Dobbins, 2005). A tactile brain-computer interface for navigation that could be used by disabled people (such as patients with amyotrophic lateral sclerosis) has even been proposed and tested (Brouwer \& van Erp, 2010).

The vast majority of those studies have drawn very positive conclusions about tactile guidance, but surprisingly users' performance was either reported incompletely or evaluated with stationary responses, that is, in the absence of orientation movements of the body. A primary aim of the present study was therefore to quantify the effectiveness of vibrotactile information in indicating a direction to turn to. Such examination is in fact essential to evaluate the potential benefits of tactile guidance, to assess the level of accuracy in spatial orientation that can be expected from tactile devices, and therefore to demonstrate that the tactile sense can actually become a new channel of information in widespread navigation assistance systems.

\section{Navigation Assistance From Tactile Devices}

The idea of communicating information through the skin was first proposed by Geldard $(1957,1960)$ and followed by the renowned research of Bach-y-Rita and colleagues on visuotactile substitution (e.g., Bach-y-Rita, Collins, Saunders, White, $\&$ Scadden, 1969). Since those pioneering studies, the scope of tactile-device applications has been considerably extended, and spatial orientation has become one of the major topics in the field. Several versions of vibrotactile displays ${ }^{1}$ have been proposed to assist navigation: a single vibrator worn on the wrist (Marston et al., 2007) or included in a mobile device (Ghiani et al., 2009; Pielot, et al., 2011), $3 \times 3$ matrix of vibrators placed on the user's back (Srikulwong, \& O'Neill, 2010; Tan, Gray, Young, \& Traylor, 2003), vibrators set in a car seat in an $8 \times 8$ matrix form (de Vries, van Erp, \& Kiefer, 2009) or in a linear array located under each thigh (van Erp \& Van Veen, 2004). But the most studied vibrotactile displays (and in all likelihood the most effective; Srikulwong \& O'Neill, 2010) are belts composed of several vibrators ( 8 in most cases) that indicate the direction to turn to by a vibration at the corresponding location around the waist $^{2}$ (e.g., Elliott, Redden, Pettitt, Carstens, van Erp, \& Duistermaat, 2006; Elliott et al., 2010; Grierson et al., 2009, 2011; Ho \& Spence, 2007; Lindeman et al., 2005; Tsukada \& Yasumura, 2004; van Erp, 2005, 2008; van Erp et al., 2005). For example, a vibration located on the spine informs the user to turn around.

Because the torso is relatively stable compared to the limbs, it is a good candidate site for delivering directional information (Cholewiak, Brill, \& Schwab, 2004). In addition, and more importantly, the advantage of such a presentation of directional information is that the location of the stimulation is directly associated with an external direction, an effect called the "tapon-the-shoulder" principle (van Erp \& van Veen, 2004; van Erp

${ }^{1}$ Electrotactile displays in a matrix form placed on the abdomen (Segond, Weiss, \& Sampaio, 2005) or on the forehead (Jansson, 1983) have also been tested for navigation assistance.

${ }^{2}$ Tactile displays consisting of vibrators distributed around the waist have also been used to indicate the direction of magnetic north (Nagel et al., 2005), perform tracking tasks (van Erp \& Verschoor, 2004), communicate information on physiological parameters in the operating room (Barralon, Dumont, Schwarz, Magruder, \& Ansermino, 2009), improve space awareness (Ferscha et al., 2008) and develop a tactile brain-computer interface for navigation (Brouwer \& van Erp, 2010).
\& Verschoor, 2004). Providing directional information in a spatialized form, that is, in a form that directly indicates a location in the environment, is an idea that has been put forward for other navigation assistance displays using auditory information. For example, the Personal Guidance System conveys locations of waypoints and landmarks using virtual spatialized sound played through earphones, so that the signal appears to come from a particular direction and distance in space (e.g., Loomis, Golledge, Klatzky, Speigle \& Tietz, 1994). This direct perceptual guidance has proved to be effective for navigation assistance (e.g., Loomis, Golledge \& Klatzky, 1998; Loomis, Marston, Golledge \& Klatzky, 2005) and has several benefits compared with speech-based guidance, including faster learning of multiple-object layouts (Klatzky, Lippa, Loomis, \& Golledge, 2002, 2003) and reduced cognitive load (Klatzky, Marston, Giudice, Golledge, \& Loomis, 2006). However, virtual sound presents the drawback of masking other auditory information that might be of importance to the user (Loomis et al., 1998, 2005; Loomis, Klatzky, \& Marston, 2007). In line with these studies, we believe in the efficiency of conveying direct spatial information to assist navigation, and argue that the tactile modality is a great alternative that frees up other senses. Among all tactile devices proposed so far for navigation assistance, vibrotactile waist-belts are the only ones that fulfill the condition of conveying directional information in a spatialized form.

Studies investigating the presentation of directional information through vibrotactile waist belts for orientation and navigation purposes can be classified into two categories depending on the response mode requested of participants. The first category of studies, which focused on the localization of the vibration, involved stationary responses: either pressing a button corresponding to the perceived location of the stimulus (Cholewiak et al., 2004), manipulating a handheld rotary dial controlling a visual cursor (van Erp, 2005, 2008), or indicating the perceived position of vibrotactile stimuli on a linear visual scale displayed on a monitor (Ho \& Spence, 2007). The second category of studies involved whole-body turning, that is, standing participants had to turn the body toward the direction indicated by the location of the vibration around the waist.

The first category of studies has raised questions about the accuracy of localization of vibrotactile stimuli presented around the abdomen, by reporting diverging biases in the responses. Cholewiak et al. (2004) used a task in which participants had to press a button corresponding to the perceived location of the vibration (a single burst of $200 \mathrm{~ms}$ ) on a cylindrical keyboard, isomorphic with a belt of 12 vibrators. They observed a bias away from the midsagittal plane (Cholewiak et al., 2004, Table 1): the majority of erroneous responses for oblique directions were toward the sides of the abdomen (i.e., away from the navel and the spine); at the remaining sites (navel, spine, left and right sides of the abdomen), errors were symmetrically distributed on either side of the target. With a task in which participants manipulated a handheld rotary dial controlling a visual cursor to indicate the direction of the vibration, van Erp (2005, Figure 5) observed a bias in the perceived direction of tactile stimulation toward the body midline: the responses were biased (up to $10^{\circ}$ for the oblique directions) toward the navel when the vibrations were located on the frontal side of the torso and toward the spine when the vibrations were located on the dorsal side.

The question of bias in the perception of vibrotactile stimuli located around the waist needs to be investigated in a task involving whole-body turning responses. In the general literature 
on spatial cognition, several behavioral measures have been used: aiming the head, pointing with the hands, turning the body to face a target, manipulating a dial, pointer, or joystick, drawing an angle or a map, giving verbal estimates... It has been shown that the nature of these behavioral measures influences the judgments of egocentric directions, that is, the directions of objects and places relative to oneself (Haber, Haber, Penningroth, Novak, \& Radgowski, 1993; Montello, Richardson, Hegarty, \& Provenza, 1999; Philbeck, Sargent, Arthur, \& Dopkins, 2008). As Philbeck et al. (2008) pointed out, "the choice of response measure is an important consideration, because, under some circumstances, one may obtain a very different pattern of results depending upon which response type is used" (p. 512). Therefore, results from tactile studies that used stationary responses may not be generalized to whole-body turning which is the actual action that tactile guidance is usually designed to assist.

Studies that involved whole-body turning (i.e., the second category of studies) present the advantage of having been conducted in an ecological context, most of them consisting of having people follow an itinerary with several waypoints in a real environment. However, quantification of the effectiveness of tactile stimulation for indicating direction is severely lacking in these studies. Some of them reported that tactile waist belts proved to be an effective navigation display, but gave no measures of heading performance (Tsukada \& Yasumura, 2004) and used waypoints of a large (15 meters) diameter (Elliott et al., 2006, 2010; van Erp et al., 2005). Other studies reported error rates for a limited number of possible answers (Grierson et al., 2009, 2011; Srikulwong, \& O’Neill, 2010). Grierson and colleagues showed that participants wearing a tactile belt composed of four vibrators were able to follow routes including several corridor intersections with no directional errors for healthy younger and older adults (Grierson et al., 2009, experiment 2) and only a few errors, apparently due to inattention, for persons with dementia (Grierson et al., 2011). With a tactile belt composed of eight vibrators, Srikulwong and O'Neill (2010) asked participants to touch the sensor corresponding to the location of the vibration on the surrounding walls, and obtained an average of 7.62 correct answers over eight possible directions.

These results support the idea that vibrotactile waist belts are an effective way of providing route information, but they only offer limited insight into the effectiveness of tactile guidance. Assessing heading performance in a binary manner (correct direction; wrong direction) may be acceptable when a discrete number of roads are possible and easily seen by the user, such as for a sighted person in an urban environment, but this evaluation is extremely insufficient if the user moves in an open field, if the user cannot apprehend the shape of the path (e.g., because of darkness, smoke, or visual impairment), or if the intended facing direction requires a fair level of accuracy (e.g., if the vibration indicates the direction of an object the user may want to reach, or a narrow path between dangerous objects or obstacles). A primary aim of the present study was therefore to quantify heading performance rigorously, in terms of speed and accuracy of body orientation, when directional information is delivered through a vibrotactile waist belt. In order to assess the potential benefits of tactile stimulation compared to a more common communication mode, we introduced a condition in which directional information was delivered in the form of spatial language (e.g., " $90^{\circ}$ to the right").

\section{Vibration Rhythm and Information-Movement Coupling}

Temporal parameters of vibratory bursts presented successively define vibration rhythm which can also be referred to as temporal pattern. These temporal features, such as burst duration and the temporal interval between bursts, have an important impact on the perception of tactile stimulation (e.g., Cholewiak, 1984; Kirman, 1974). In previous research on tactile guidance, vibration rhythms were mostly chosen arbitrarily, either with constant rates (Grierson et al., 2009, 2011; Srikulwong \& O'Neill, 2010) or with variations depending on the distance to the waypoint (Elliott et al., 2006, 2010). Only two studies using vibrotactile waist belts have tested the influence of different vibration rhythms in navigation tasks. Tsukada and Yasumura (2004) tested four vibration rhythms (125 ms on - 125 $\mathrm{ms}$ off; $250 \mathrm{~ms}$ on $-250 \mathrm{~ms}$ off; $500 \mathrm{~ms}$ on $-500 \mathrm{~ms}$ off; $840 \mathrm{~ms}$ on $-840 \mathrm{~ms}$ off) but the absence of quantification of errors in their study prevent reliable conclusions from being drawn. Van Erp et al. (2005) compared different rhythms for coding distance to the next waypoint on a route. They found no effect of these distance-coding schemes on performance (measured as the walking speed) and no benefits compared to a control condition with no distance information. However, in order to maintain an acceptable temporal resolution of spatial information, van Erp et al. (2005) advised keeping the frequency of feedback at or above a minimum of 1 vibration every 4 seconds (vibrators were activated in 1-s pulses in their study). This important recommendation, made in the most famous and cited paper on tactile displays for navigation guidance, was partly based on participants' verbal reports and requires further validation. An important consequence of the choice of vibration rhythm that has been insufficiently considered so far is that it determines the rate at which the traveler receives guidance information and therefore, how this information can be used to control turning movements. If the vibration rhythm is sufficiently high compared to the time needed to achieve a specific heading (i.e., several bursts delivered within a second), the location of tactile stimulation can be updated along with the body rotation of the user, as shown in Figure 1 for the case of a waist belt composed of 8 vibrators. This alternative, rarely applied in previous research on tactile guidance (but see Marston et al., 2007, and Ghiani et al., 2009), is made possible by using data from the electronic compass that is usually integrated in recent tactile devices designed to assist navigation (e.g., Grierson et al., 2009; Tsukada \& Yasumura, 2004; van Erp et al., 2005; Zelek \& Holbein, 2008). The update of the location of tactile stimulation would have the great advantage of creating a reciprocal relation between perception and motor action (which exists in "natural", unenhanced perception; e.g., Gibson, 1966) for the vibrotactile modality. In contrast, if the vibration rhythm is low (e.g., one burst every 5 seconds), the traveler receives information about the direction to turn to before the action, and body rotation is achieved with no further information from the vibrotactile device.

Whether coupling spatial information to movement might be beneficial to heading performance relates to the question of the role of concurrent perceptual information in controlling directed actions (e.g., Loomis \& Beall, 2004; Warren, 1998, 2006). Several studies have shown that when people are presented a visual stimulus or an auditory stimulus (3-D sound or spatial language such as "1 o'clock") about a target location and are 


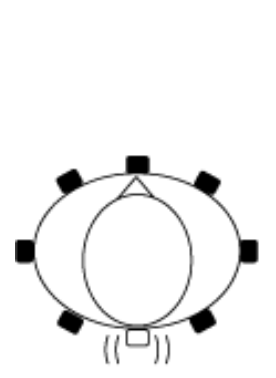

(a)

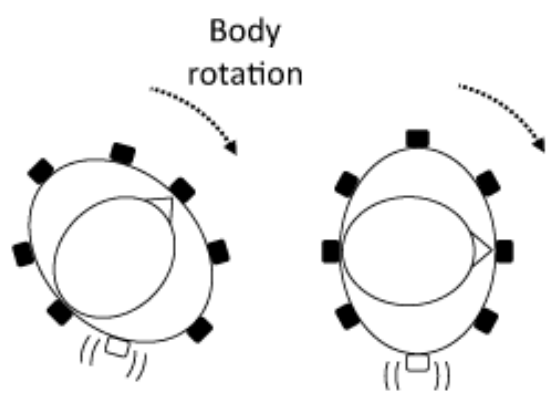

(b)

(c)

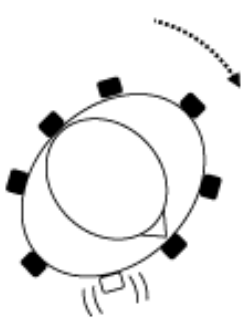

(d)

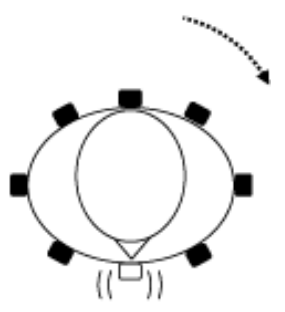

(e)

Figure 1. Illustration of the updating of spatial information that can be obtained with a vibrotactile waist belt (bird's eye view). The activated vibrator is depicted in white. In this example, the requested direction is $180^{\circ}$ : at first, the vibrator located on the spine is activated (a). As the participant turns clockwise, the site of stimulation moves in counterclockwise direction: the location of the vibration continuously indicates the requested direction relative to the current orientation of the participant (b to e).

then prevented from receiving further information about the stimulus, they are able to update the location of the target initially seen or heard while moving about in space (e.g., Loomis, Lippa, Klatzky, \& Golledge, 2002; Loomis, Da Silva, Fujita, \& Fukusima, 1992; Rieser, 1989; Thomson, 1983). According to these results, one could expect that turning the body to a requested direction can be successfully achieved from a single burst that precedes body movement, and therefore, that low vibration rhythms can be effective.

In contrast, the ecological approach emphasizes the role of concurrent information about the relation between the agent and the environment in guiding behavior (e.g., Gibson, 1966, 1979; Warren, 1998, 2006). A way to apply this perspective to the design of navigation assistance systems is to provide tactile information so as to continuously specify the intended direction relative to the current heading of the user. Following this line of reasoning, a natural hypothesis would be that updating the location of tactile stimulation during body rotation by means of a sufficient vibration rhythm will lead to better performance than a single stimulus delivered before the action.

In the present study, we examined whether coupling tactile stimulation with the user's movements influences heading performance by testing two vibration rhythms: the threshold pattern recommended by van Erp et al. (2005), namely $1 \mathrm{~s}$ on -4 $\mathrm{s}$ off, that provides a single burst prior to body rotation, and a more frequent pattern, $200 \mathrm{~ms}$ on $-200 \mathrm{~ms}$ off, which allows the update of tactile stimulation during body movements.

\section{The Present Study}

In the present study, we assessed the effectiveness of vibrotactile information in indicating a direction to turn to when information-movement coupling was provided and when it was not. We also measured the potential benefits of tactile guidance compared to spatial language in terms of response time and accuracy of body orientation. Such a quantification of heading performance is in fact necessary to provide reference values that can be used to determine whether tactile guidance may be a suitable means of conveying directional information depending on the accuracy requested by the considered task (e.g., reaching a location, avoiding obstacles, grasping an object) and context (e.g., nature and dangerousness of the environment, level of spatio-temporal constraints, potential impairment of the user).

In order to match what the user's behavior would be in an ecological context, we chose whole-body rotation (i.e., rotating one's body to face the indicated direction) to assess the user's ability to exploit directional information ${ }^{3}$. Participants were asked to rotate the body in order to face the direction indicated by three guidance modes. In the verbal condition, the direction to turn to was delivered before body rotation in the form of spatial language, expressed in degrees (e.g., " $45^{\circ}$ to the left"). In the long tactile mode (LT-mode), a $1 \mathrm{~s}$ on $-4 \mathrm{~s}$ off rhythm produced a single vibration before body rotation. In the short tactile mode (ST-mode), a $200 \mathrm{~ms}$ on - $200 \mathrm{~ms}$ off rhythm provided information-movement coupling from the update of vibrotactile stimulation during body rotation.

We also assessed the influence of the absence of visual information for the three guidance modes by testing participants with full light and in complete darkness. In fact, one of the purposes of tactile guidance is to assist navigation in poor visual conditions (including visual impairment). Therefore, it is important to test the effectiveness of the tactile device when visual access to environmental information is prohibited. We expect that tactile information will compensate for the absence of visual information (e.g., Jones \& Sarter, 2008; van Erp \& Self, 2008).

\section{Method}

\section{Participants}

Twelve participants (five women and seven men) took part in the experiment. Their mean age was 20.79 years (range: $16-$ 24). All reported having normal or corrected-to-normal vision, and no hearing or sense-of-touch disorders. None of them had previously worn or experienced vibrotactile displays. Each participant signed an informed consent statement after receiving oral and written descriptions of the procedure.

${ }^{3}$ In fact, actual locomotion toward a goal is likely to add only the error of straight-line walking to body rotation (e.g., Montello et al., 1999). 


\section{Apparatus}

Figure 2 illustrates the set-up used in this experiment. The tactile device (CAYLAR, Villebon-sur-Yvette, France) used in this experiment was placed in a hip bag and consisted of an embedded microcomputer, a battery, and a set of 80 vibrators connected to independent wires of $80 \mathrm{~cm}$. The device also included a global positioning system, a magnetic compass, and a three axes sensor that were not used in the present study. The vibrators were small cylinders (length of $20 \mathrm{~mm}$ and diameter of $4 \mathrm{~mm}$ ) vibrating at $190 \mathrm{~Hz}$. They were strapped on the skin longitudinally, parallel to the craniocaudal body axis, creating a contact area of about $0.8 \mathrm{~cm}^{2}$.

The vibrators were placed around the waist of the participant, so as to denote the eight directions that participants were requested to turn to: $0^{\circ}, 180^{\circ}$, and $45^{\circ}, 90^{\circ}, 135^{\circ}$ to the left or to the right of the participant's initial facing direction. The vibrator indicating $0^{\circ}$ (straight ahead) was placed above the navel, at waist level (about $3 \mathrm{~cm}$ above the navel), and the location of the other vibrators was determined from this reference location. To ensure that the vibrations indicated the external directions accurately, the vibrators were not distributed evenly around the waist, but their location was individually adjusted depending on the eccentricity of the abdomen of each participant. Assuming the shape of the abdomen to be elliptical, we measured its size at
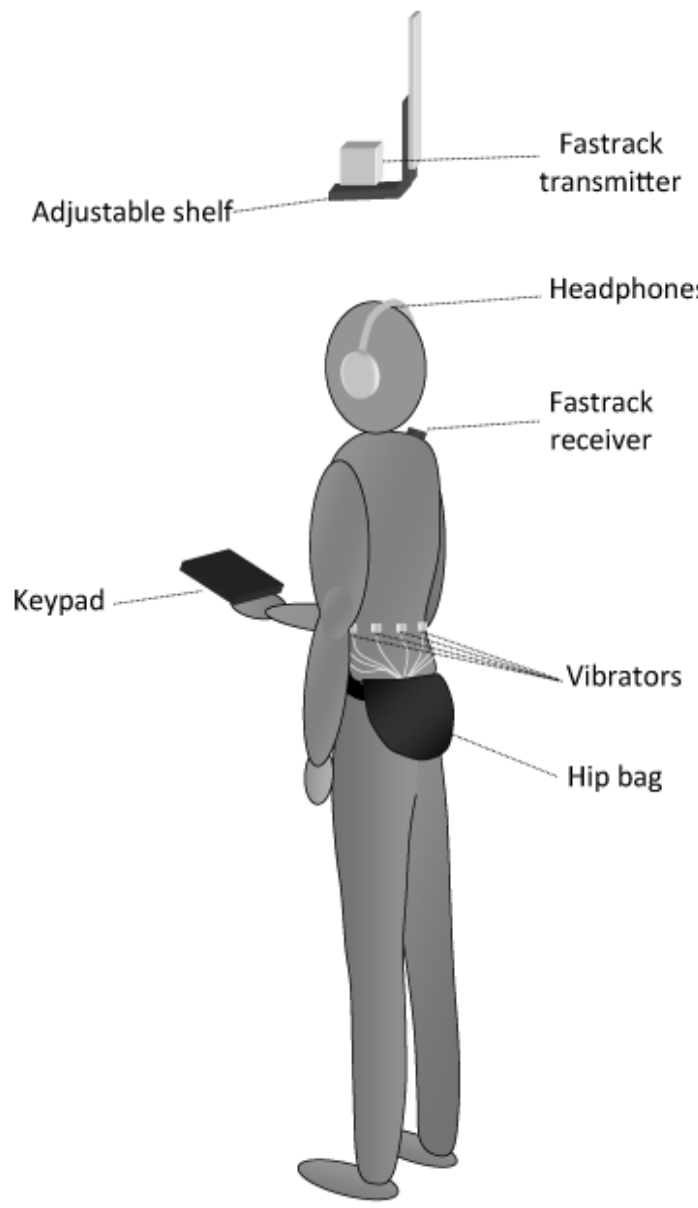

Figure 2. Schematic view of the experimental set-up.

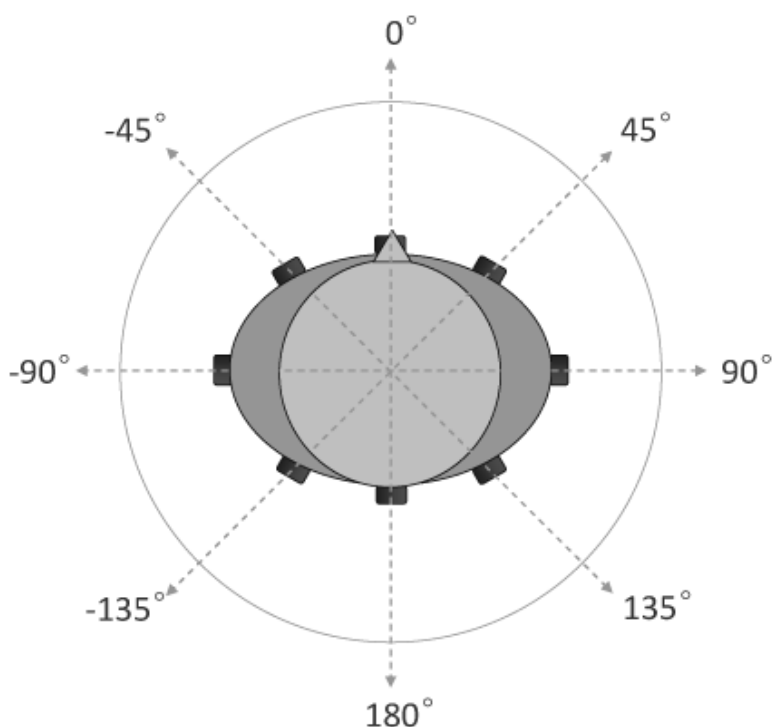

Figure 3. Location of the eight vibrators (in black) around the waist that defined sectors of $45^{\circ}$ and indicated the eight requested directions to turn to (bird's eye view).

waist level along the major (lateral) and minor (antero-posterior) axes with a measuring rod, and then computed the positions of the vibrators so that they defined sectors of $45^{\circ}$ (Figure 3 ). To do so, we used elliptic equations to compute the Cartesian coordinates of the points corresponding to the requested angles and used these coordinates to compute the distance between the point located above the navel and the subsequent points along the perimeter of the abdomen. Vibrators were fixed at the seven resulting distances using a measuring tape placed around the waist. During a preliminary experiment, we ensured that, once strapped on the skin, the activated vibrators did not produce any noise that could be heard by the participant.

We used a magnetic tracking system to collect orientation data (Fastrak, Polhemus, Inc., Colchester, VT). The receiver was attached to the skin on the right shoulder (on the lateral quarter of the upper trapezius) using hypoallergenic double-sided adhesive and medical cloth tape. The transmitter was located above the head of the participant, on a shelf fixed to the ceiling that could be adjusted to the participant's height so that the distance between the transmitter and the receiver did not exceed $60 \mathrm{~cm}$. Six degree-of-freedom position and orientation data were collected from the receiver at $60 \mathrm{~Hz}$ and stored on disk for later analysis. Azimuth data were also used in real time to update the location of the vibrotactile stimulation according to changes in the participant's heading.

Participants wore headphones that covered the ears (Audio 995H, Plantronics, Inc., Santa Cruz, CA) so they could hear directional information when it was provided verbally. They also held a keypad to validate their answers (i.e., body orientation) at each trial.

\section{Design}

Directional information was delivered following three guidance modes. In the verbal condition, pre-recorded 
instructions expressed in degrees ${ }^{4}$ (e.g., " $90^{\circ}$ to the right") were played via the headphones at the beginning of a trial. In the two tactile modes, the requested direction was indicated by the location of the vibration. In the long tactile mode (LT-mode), the duration of the vibratory bursts was $1 \mathrm{~s}$ and the temporal interval between vibrations was $4 \mathrm{~s}$. In the short tactile mode (ST-mode), the duration of the vibratory bursts was $200 \mathrm{~ms}$ and the temporal interval between vibrations was $200 \mathrm{~ms}$. The location of the vibrations was updated according to changes in the participant's facing direction. In the TL-mode, the time needed to rotate the body was shorter than the temporal interval between two vibrations, resulting in the perception of a single vibratory burst of $1 \mathrm{~s}$ (none of the participants reported the perception of a second burst in this condition, which is in accordance with the movement times we recorded). In the ST-mode, the rotation of the body was accompanied by a displacement of the vibration on the abdomen (Figure 1). The tactile stimulation stopped when the participants validated their final heading by pressing a key on the keypad they were holding.

The task was executed in two visual conditions: normal light and total darkness. The $7 \mathrm{~m} \times 5 \mathrm{~m}$ room in which the experiment took place contained various experimental equipment, including computers, desks, chairs, and a semi-circular screen used for other experiments. Every aperture in the walls created by door frames and windows were sealed with opaque adhesive paper and thick curtains. In addition, every light source related to the functioning of electronic devices was covered. In the light condition, the room was well-lit by six fluorescent ceiling lights, providing participants with multiple sources of contextual visual information that could contribute to spatial orientation. In the darkness condition, the ceiling lights were turned off, plunging the room into total darkness.

\section{Procedure}

Prior to the start of the experimental session, the experimenters took the measurements of the abdomen (see above) and computed the locations of each vibrator using a predefined spreadsheet. Vibrators were fixed directly onto the skin at the corresponding locations with medical cloth tape, and participants were given the headphones and the keypad. To ensure that the devices functioned properly, participants were given the eight verbal instructions successively through the headphones and were asked to confirm that they had heard them. Vibrotactile stimuli from each of the eight positions were then delivered successively for $1 \mathrm{sec}$ and participants were asked to indicate the location of the vibration with their hands.

Afterward, participants followed a familiarization session for each guidance mode: verbal, long tactile and short tactile. For each guidance mode, the eight directions were randomly presented once. Participants were asked to turn to the requested direction, to confirm their answer by pressing a key on the keypad they were holding, and to wait for the next instruction triggered by the experimenter.

The experimental session consisted of six blocks corresponding to the six possible combinations of guidance and

${ }^{4}$ Participants were asked whether they found it easier to head to a requested direction from verbal information expressed in degrees (e.g., "90 to the right") or in clock position (e.g., "3 o'clock"). Half of them (6) answered that they preferred the directions to be expressed in degrees, 3 had no preference, and only 3 preferred the clock-face directions. vision conditions. Block order was randomized across the participants, with the only restrictions that the first block was always conducted in normal light and that light and darkness conditions were always presented alternately (whether they involved the same guidance mode or not). Within each block, each of the eight directions was presented five times, resulting in 40 completely randomized trials per block. The mode of response was the same as in the familiarization session. Participants never received feedback about the accuracy of their performance.

After the experiment, participants completed a questionnaire that asked them to score easiness ("Did you find the task easy to perform?"), intuitiveness ("Did you find the directional information intuitive?") and perceived accuracy ("Do you think your responses were accurate?") for each guidance mode. Ratings were based on a scale from 1 (very difficult, not intuitive at all, very inaccurate) to 6 (very easy, very intuitive, very accurate). Finally, the participants were asked which guidance mode they preferred (verbal mode, long tactile mode, short tactile mode, or no preference). Altogether, the experiment took about 45 minutes to complete.

\section{Data Analysis}

Heading performance was evaluated from the azimuth of the torso collected by the magnetic tracking system using four dependent variables. Heading accuracy was measured in terms of constant error $(C E)$, indicating the tendency to undershoot or overshoot the requested direction, and absolute error $(A E)$, indicating the magnitude of the error.

$C E$ was calculated as the difference between the final heading and the direction indicated by the (verbal or tactile) instruction. An underestimation of the requested direction (i.e., insufficient rotation of the body, with a bias toward $0^{\circ}$ ) resulted in a negative constant error, and an overestimation (i.e., rotation of the body exceeding the requested direction, with a bias toward $180^{\circ}$ ) resulted in a positive constant error. By convention, when the requested direction was $180^{\circ}$, we considered the direction of body rotation to define the sign of the constant error: a response of $170^{\circ}$ resulted in a negative constant error if the participant turned to the right (insufficient rotation of the body) and a positive constant error if the participant turned to the left (excessive rotation of the body). $A E$ corresponded to the absolute value of $C E$, and indicated the magnitude of error regardless of its direction.

As a measure of within-participants variability, we computed variable error $(V E)$ as the standard deviation of $C E$ for each requested direction across the 5 trials per condition. Finally, response time corresponded to the delay between launching the directional information (either verbal or tactile) and the participant's validation of the heading response from the keypad.

Heading and its derivatives $(C E, A E$, and $V E)$ are circular variables and may require the use of circular statistics. However, when the range of the distribution does not exceed $180^{\circ}$ (which was the case in the present study in every condition), circular statistics (Batschelet, 1981; Mardia \& Jupp, 2000) and regular linear statistics result in virtually identical outcomes. Accordingly, we did not use circular methods to compute descriptive or inferential statistics. We performed separate analyses of variance (ANOVA) on $C E, A E, V E$, response time, and qualitative scores. The $p$ value levels were corrected for possible deviations from sphericity using the Huynh-Feldt 
epsilon $(\varepsilon)$. When appropriate, we report the uncorrected degrees of freedom, the $\varepsilon$ value, and the $p$ value according to the corrected degrees of freedom.

\section{Results}

\section{Vibrators Location}

Because the human abdomen presents an elliptical rather than a circular shape, the procedure followed in this experiment tends to slightly reduce the distance between vibrators located near the midsagittal plane compared to an even distribution around the waist. The mean eccentricity of the abdomen measured for the group of 12 participants was $e=0.68$, with a minimum of 0.62 and a maximum of 0.75 . While the locations of the vibrators for the cardinal directions $\left(0^{\circ}, 180^{\circ},+90^{\circ}\right.$ and $\left.-90^{\circ}\right)$ were identical to an even distribution around the waist, vibrators for the intermediate directions were on average $0.98 \mathrm{~cm}$ closer to the spine (for $+45^{\circ}$ and $-45^{\circ}$ ) or navel (for $+135^{\circ}$ and $-135^{\circ}$ ), with a minimum difference of $0.69 \mathrm{~cm}$ and a maximal difference of $1.38 \mathrm{~cm}$ (depending on the eccentricity of the abdomen). These locations accurately specified the external directions participants were asked to turn to (Figure 3).

\section{Heading Accuracy}

For each indicator of heading accuracy $(C E, A E$, and $V E)$, we conducted a Guidance (Verbal, LT, ST) $\times$ Vision (light vs. darkness) $\times$ Direction (8) ANOVA with repeated measures on each factor. The pattern of results was similar for all three variables, with significant main effects of guidance and direction, significant Guidance $\times$ Direction interactions, and no other significant effects. Thus, we report the statistics for $C E, A E$ and $V E$ together below. Note that the values reported in this section include heading errors for the direction of $0^{\circ}$, which required no movement from the participants.

Table 1 shows descriptive statistics for heading accuracy according to the three guidance modes. The ANOVAs revealed significant main effects of guidance on $C E, F(2,22)=5.06, p=$ $.016, \eta_{\mathrm{p}}^{2}=.32$, on $A E, F(2,22)=11.39, p<.001, \eta_{p}^{2}=.51$, and on $V E, F(2,22)=8.23, p=.002, \eta_{p}^{2}=.43$. Tukey's post hoc analyses revealed that the ST-mode led to smaller errors than the LT-mode and the verbal mode for $C E$ ( $p s \leq .05), A E(p s \leq .002)$ and $V E(p s \leq .03)$. No difference was found between the LTmode and the verbal mode ( $p s \geq .52)$. These results show that heading accuracy was superior for the ST-mode: the magnitude of error was lower $(A E)$, the tendency to overshoot the requested direction was reduced $(C E)$, and the within-participant consistency was higher (lower variable error, $V E$ ) than for both the verbal mode and the LT-mode.

The ANOVAs also revealed significant main effects of direction on $C E, F(7,77)=11.34, \varepsilon=.86, p<.001, \eta_{p}^{2}=.51$, on $A E, F(7,77)=20.10, \varepsilon=.76, p<.001, \eta_{p}{ }^{2}=.65$, and on $V E, F(7$, $77)=33.60, p<.001, \eta_{p}^{2}=.75$. For $C E$, Tukey's post hoc analyses revealed that heading responses were less biased ( $p s \leq$ $.007)$ for $0^{\circ}\left(M=0.00^{\circ}, S E=0.16^{\circ}\right)$ and $180^{\circ}\left(M=3.02^{\circ}, S E=\right.$ $\left.2.46^{\circ}\right)$ than for the other directions $\left(+10.62^{\circ}<M<+13.09^{\circ}\right.$, $1.56^{\circ}<S E<2.54^{\circ}$ ). No other differences were significant for $C E$. For $A E$, Tukey's tests showed only two significant results. First, and unsurprisingly, absolute heading error was lower ( $p s<$ $.001)$ for $0^{\circ}\left(M=0.86^{\circ}, S E=0.15^{\circ}\right)$ than for all other directions $\left(11.00^{\circ}<M<16.68^{\circ}, 1.21^{\circ}<S E<2.11^{\circ}\right)$. Second, $A E$ was lower $(p=.01)$ for $180^{\circ}\left(M=11.00^{\circ}, S E=1.21^{\circ}\right)$ than for $+135^{\circ}$ $\left(M=16.68^{\circ}, S E=1.95^{\circ}\right)$.

The pattern of results was more complicated for $V E$, with $-45^{\circ}$ $\left(M=7.38^{\circ}, S E=0.52^{\circ}\right)$ leading to less variable responses $(p s \leq$ $.004)$ than $\pm 90^{\circ}$ and $\pm 135^{\circ}\left(10.98^{\circ}<M<12.91^{\circ}, 0.76^{\circ}<S E<\right.$ $\left.1.18^{\circ}\right),+45^{\circ}\left(M=8.20^{\circ}, S E=0.90^{\circ}\right)$ leading to less variable responses $(p s \leq .021)$ than $+90^{\circ}$ and $\pm 135^{\circ}\left(11.33^{\circ}<M<12.91^{\circ}\right.$, $\left.0.76^{\circ}<S E<1.18^{\circ}\right), 180^{\circ}\left(M=9.30^{\circ}, S E=0.57^{\circ}\right)$ leading to less variable responses $(p=.004)$ than $+135^{\circ}\left(M=12.91^{\circ}, S E=\right.$ $\left.0.76^{\circ}\right)$, and again, lower values for $0^{\circ}\left(M=1.07^{\circ}, S E=0.20^{\circ}\right)$ than for all other directions $(p s<.001)$. To sum up, withinparticipant variability tended to be lower for $0^{\circ}$ and $\pm 45^{\circ}$.

The ANOVAs finally revealed significant Guidance $\times$ Direction interactions for $C E, F(14,154)=2.68, p=.002, \eta_{p}{ }^{2}=$ .20 , for $A E, F(14,154)=2.30, p=.007, \eta^{2}=.17$, and for $V E$, $F(14,154)=2.92, p<.001, \eta_{p}^{2}=.21$. Figure 4 shows that heading accuracy tended to be more uniform across the different requested directions for the ST-mode than for the verbal mode and the LT-mode. In addition, differences in heading accuracy according to the guidance mode depended on the required directions. Tukey's post hoc analyses conducted on $A E$ revealed that the magnitude of error was significantly lower with the STmode than with the verbal mode for all directions but $0^{\circ}, 180^{\circ}$ and $+90^{\circ}$ ( $\left.p s \leq .015\right)$. $A E$ was also lower with the ST-mode than with the LT-mode for $\pm 90^{\circ}$ and $\pm 135^{\circ}$ ( $p s \leq .023$ ). There was no significant difference between the verbal mode and the LT-mode in the comparisons per direction ( $p s \geq .41$ ), and no significant difference across guidance modes for the directions of $0^{\circ}$ and $180^{\circ}$ ( $p s \geq .99$ ). The ANOVAs revealed no other main effects or interactions for $C E, F s \leq 0.52, p s \geq .71, \eta p^{2} \leq .04$, for $A E, F s \leq$ $4.38, p s \geq .06, \eta_{p}^{2} \leq .28$, and for $V E, F s \leq 2.87, p s \geq .08, \eta_{p}^{2} \leq$ .21 .

Table 1

Heading performance measures in the three guidance modes conditions.

\begin{tabular}{|c|c|c|c|c|c|c|}
\hline \multirow[b]{2}{*}{ Measure } & \multicolumn{2}{|c|}{ Verbal mode } & \multicolumn{2}{|c|}{ Long tactile mode } & \multicolumn{2}{|c|}{ Short tactile mode } \\
\hline & $M(S E)$ & $95 \% C I$ & $M(S E)$ & $95 \% C I$ & $M(S E)$ & $95 \% C I$ \\
\hline$C E$ & $10.74(2.22)$ & {$[5.85,15.63]$} & $10.04(2.15)$ & {$[5.30,14.78]$} & $6.27(1.05)$ & {$[3.95,8.58]$} \\
\hline$A E$ & $14.16(1.71)$ & {$[10.40,17.92]$} & $13.59(1.71)$ & {$[9.82,17.35]$} & $8.90(0.89)$ & {$[6.94,10.86]$} \\
\hline$V E$ & $10.38(0.79)$ & {$[8.65,12.11]$} & $9.53(0.76)$ & {$[7.86,11.21]$} & $7.37(0.46)$ & {$[6.35,8.39]$} \\
\hline
\end{tabular}

Note. $M=$ Mean; $S E=$ standard error; $95 \% C I=95 \%$ confidence interval; $C E=$ constant error; $A E=$ absolute error; $V E=$ variable error. 

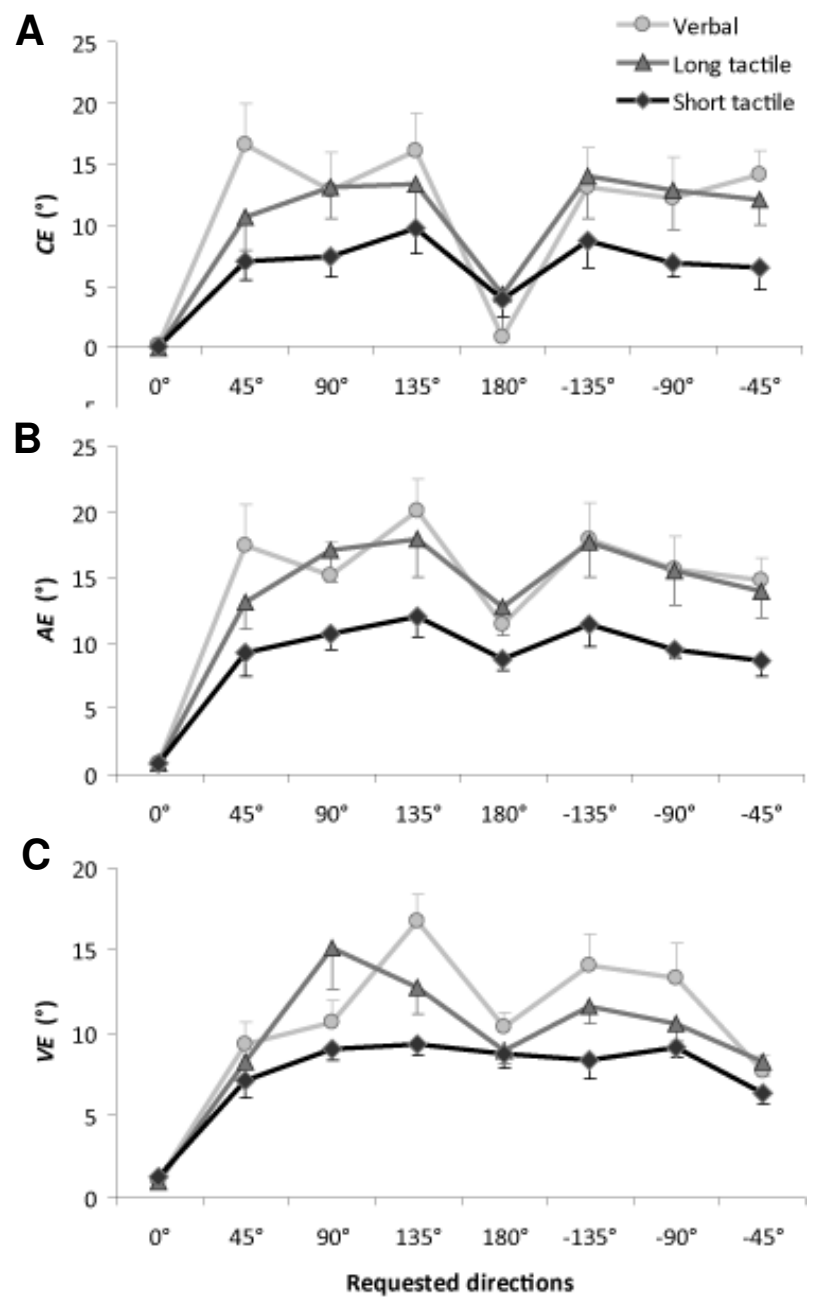

Figure 4. Mean values of heading accuracy for the eight required directions with verbal, long tactile, and short tactile guidance modes. A: Constant error, $C E$, indicating the direction of error (positive values indicate that the rotation of the body exceeded the requested direction). B: Absolute error, $A E$, indicating the magnitude of error $\mathrm{C}$ : Variable error, $V E$, indicating the within-participant variability. The error bars represent standard error (between-subjects variability).

Figure 5 presents another illustration of the results that matches the spatial representation of the data to heading responses in a straightforward manner. In these circular diagrams, heading error can be deduced from the difference between the radial dashed lines (requested directions) and the shaded areas (final heading).

\section{Influence of Vision Condition}

In the ANOVAs presented in the previous section, no effect of vision was significant. Because specific differences for one guidance mode can fade in the overall analysis of variance, and because we specifically and a priori expected that the darkness condition may not have the same effects depending on the guidance mode, we conducted planned comparisons to assess the
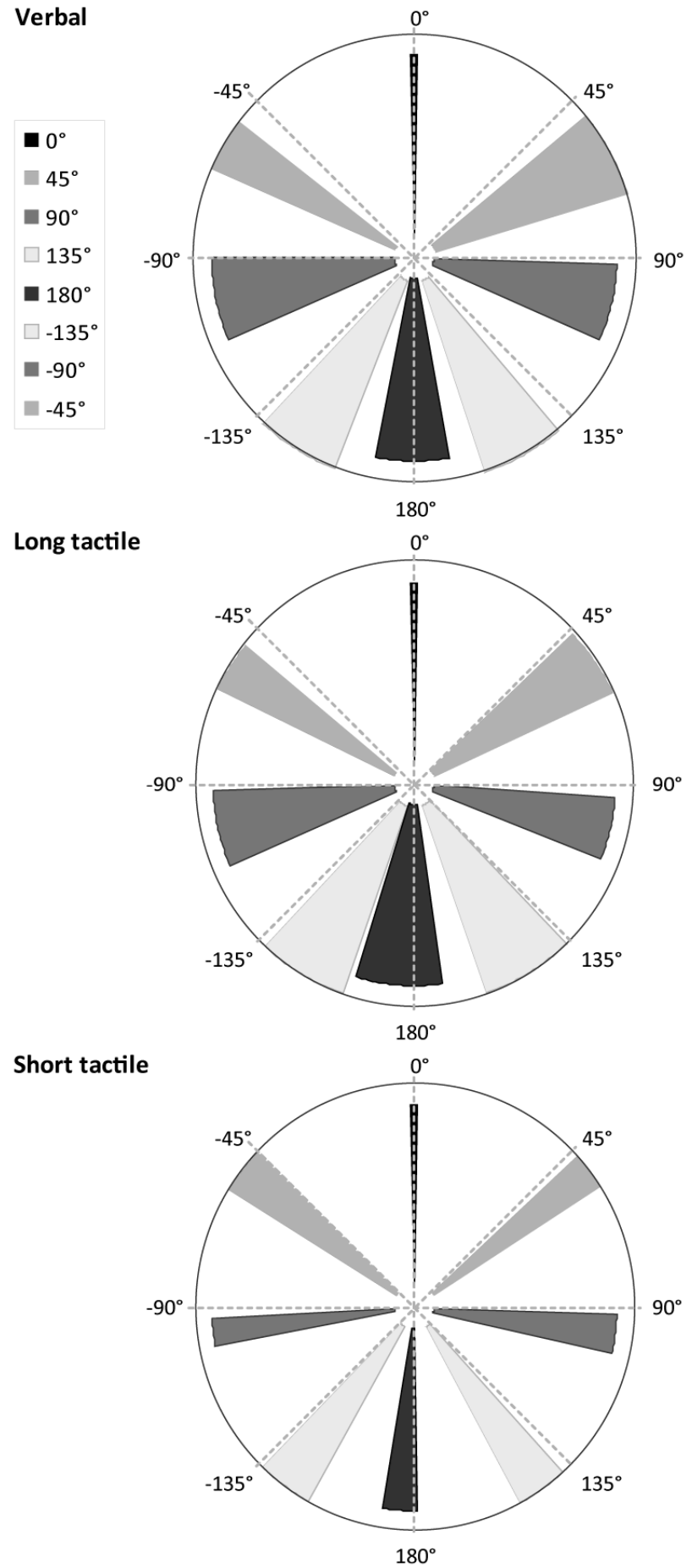

Figure 5. Mean heading responses for the three guidance modes: shaded areas represent the mean body heading \pm 1 SD for each of the eight requested directions (from $0^{\circ}$ to $-45^{\circ}$, represented by the dashed radial lines). 
consequences of vision conditions on absolute heading accuracy for the three guidance modes. We found that $A E$ was significantly higher in the darkness condition than in the normal light condition for the verbal mode, $t(1,11)=7.58, p=.019, \eta p^{2}$ $=.41$, whereas there was no influence of vision condition for the ST-mode or the LT-mode, $t s(1,11)=.48, p s=.50, \eta_{p}{ }^{2}=.04$ (Figure 6). These results show that heading accuracy was impaired in total darkness for the verbal mode but not for the tactile modes.

\section{Response Time}

Mean response times are presented in Figure 7 for the three guidance modes and the eight required directions. A Guidance (3) $\times$ Vision (2) $\times$ Direction (8) ANOVA with repeated measures conducted on response time (Figure 7 , top panel) revealed a significant main effect of guidance, $F(2,22)=95.13, p<.001$, $\eta_{p}{ }^{2}=.90$. Tukey's post hoc analyses showed that response time was significantly longer for the verbal mode $(M=3.92 \mathrm{~s}, S E=$ $0.12)$ than for the tactile modes $(p s<.001)$ which did not differ from each other (LT: $M=2.95 \mathrm{~s}, S E=0.14 ; \mathrm{ST}: M=2.93 \mathrm{~s}, S E$ $=0.13 ; p=.96)$. The ANOVA also revealed a significant main effect of vision: response time was significantly longer in total darkness $(M=3.32 \mathrm{~s}, S E=0.13)$ than in normal light condition $(M=3.21 \mathrm{~s}, S E=0.13), F(1,11)=6.84, p=.024, \eta^{2}=.38$. The main effect of direction was also significant, $F(7,77)=434.67, \varepsilon$ $=.55, p<.001, \eta_{p}{ }^{2}=.97$, indicating unsurprisingly that the response time increased with the magnitude of body rotation required by the requested direction.

Finally, the ANOVA showed a significant Guidance $\times$ Direction interaction, $F(14,154)=26.35, p<.001, \eta_{p}{ }^{2}=.71$, indicating that response time for the verbal mode did not increase as gradually with the magnitude of the rotation as for both tactile modes (Figure 7, top panel). It should be pointed out that this effect is due to the amount of time necessary to present the different verbal instructions (e.g., it takes longer to say " $135^{\circ}$ to the left" than "180") and that it disappears when stimulus duration is subtracted from the response time (Figure 7, bottom

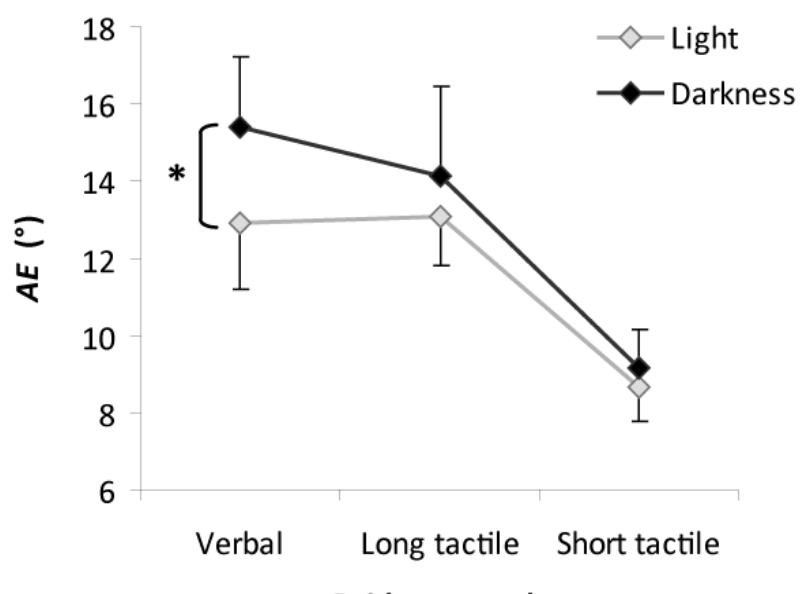

Guidance mode

Figure 6. Absolute heading error for the three guidance modes and the two vision conditions (normal light and total darkness). The error bars represent standard error (between-subjects variability). The asterisk indicates the significant difference between vision conditions for the verbal mode $(\mathrm{p}=.019)$. $\mathrm{AE}=$ absolute error.
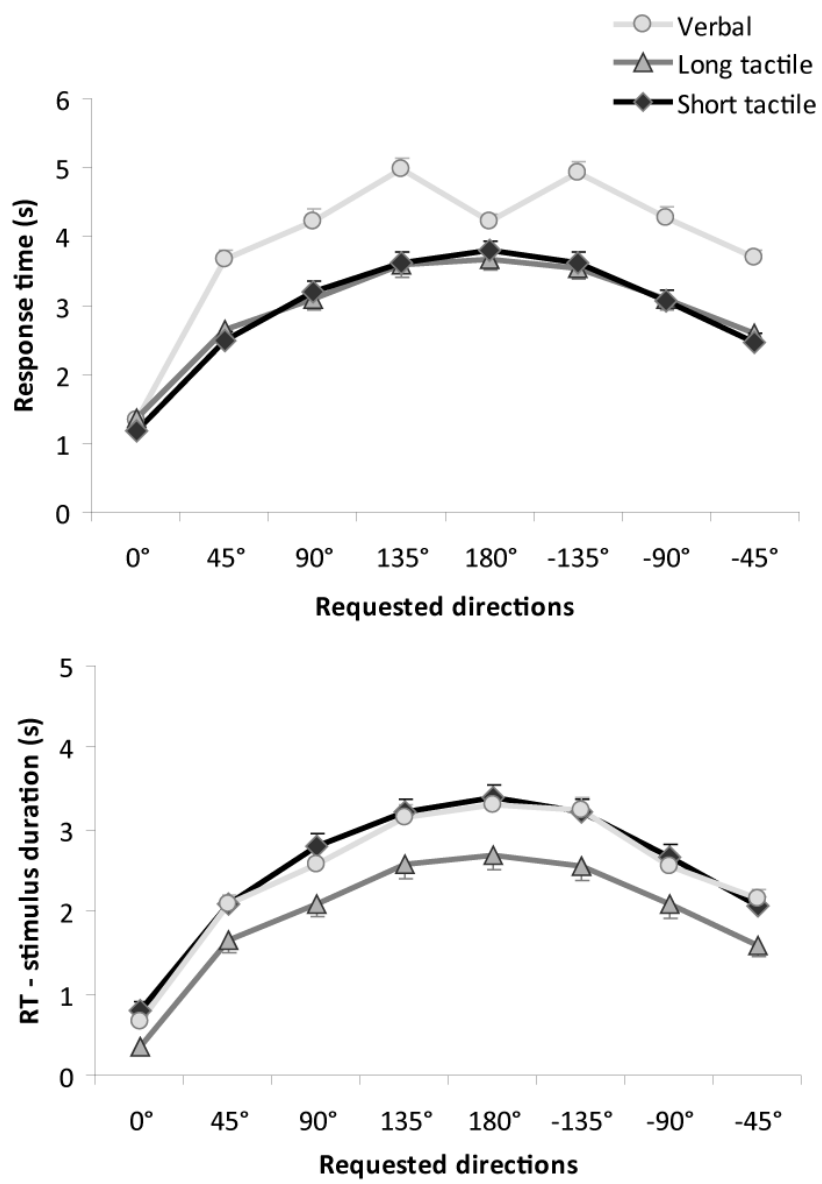

Figure 7. Speed of body rotation for the eight requested directions and the three guidance modes. The error bars represent standard error (between-subjects variability). Top panel: Response time (delay between launching the directional information and validation of final heading). Lower panel: Response time (RT) minus stimulus duration. Stimulus duration ranged from $0.68 \mathrm{~s}$ to $1.85 \mathrm{~s}$ for the verbal mode depending on the time needed to pronounce the requested direction, it corresponded to $1 \mathrm{~s}$ for the LT-mode, and it was considered to be $0.40 \mathrm{~s}$ for the ST-mode (only the first burst of vibration and inter-vibration interval were taken into account).

panel). Note that only the first burst of vibration and intervibration interval were taken into account in defining stimulus duration for the short tactile mode: stimulus duration was considered to be $400 \mathrm{~ms}$ for the ST-mode in Figure 7B. For the verbal mode, the duration of the stimulus corresponded to the duration of the audio files and ranged from $0.68 \mathrm{~s}$ (corresponding to " $0^{\circ}$ ) to $1.85 \mathrm{~s}$ (corresponding to " $135^{\circ}$ to the right"). For the LT-mode, the duration of the stimulus was $1 \mathrm{~s}$. The ANOVA conducted on response time revealed no other significant interaction, $F s \leq 2.07, p s \geq .06, \eta_{p}^{2} \leq .16$.

\section{Qualitative Scores}

One-way ANOVAs with repeated measures revealed that the main effect of guidance was significant for each qualitative score (easiness, intuitiveness, and perceived accuracy), $F s(2,22) \geq$ 11.63, $\varepsilon \leq .79, p s \leq .002, \eta_{p}^{2} \geq .51$ (Figure 8). Tukey's post hoc analyses showed that all ratings were significantly higher for the 
ST-mode than for the verbal mode $(p s<.001)$ and the LT-mode $(p s \leq .031)$. The verbal mode and the LT-mode significantly differed for the intuitiveness score $(p=.012)$ but not for the two other ratings ( $p s \geq .11$ ).

To the question "Overall, which guidance mode did you prefer?", 10 of the 12 participants $(83.33 \%)$ answered that they preferred the ST-mode. The 2 other participants (16.67\%) answered that they preferred the verbal mode.

\section{Discussion}

The present research demonstrates the special efficiency of tactile stimulation in indicating a direction to turn to when its rhythm allows the coupling of stimulation and movement. This result is consistent for both heading accuracy measures and subjective ratings. Compared to verbal guidance, tactile guidance, regardless of vibration rhythm, also allowed faster responses (spatial information was conveyed more quickly with tactile stimuli than with spatial language) and did not impair heading accuracy in the absence of vision.

\section{Heading Accuracy: Effects of Guidance Mode}

The most important finding of our study is that tactile guidance proved to be more effective than spatial language when the temporal parameters of tactile stimulation allow the updating of directional information. In fact, our results showed that participants' performance highly benefited from the coupling of body movements and vibratory stimulation inherent to the short tactile mode. Van Erp et al. (2005) advised keeping the frequency of feedback at or above a minimum of 1 vibration every 4 seconds. Applying this minimum threshold implies that body rotation is achieved with no concurrent tactile input. A major contribution of the present study in the expanding literature on tactile displays is to reveal and quantify the importance of vibration rhythm and information-movement coupling on heading error. For the long tactile mode (which

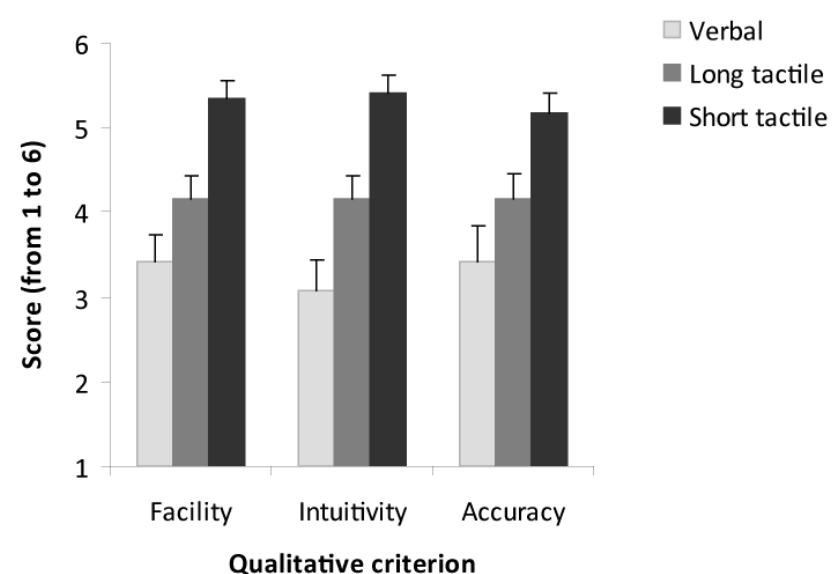

Figure 8. Mean ratings for easiness, intuitiveness and perceived accuracy for the three guidance modes on a scale from 1 (very difficult, not intuitive at all, very inaccurate) to 6 (very easy, very intuitive, very accurate). The error bars represent standard error (between-subjects variability). followed the recommendation of van Erp and collaborators), the magnitude of heading error was 1.5 times that of the short tactile mode (Table 1).

An interesting way to interpret the values of heading error observed in the present study is to estimate their consequences in units of distance (Figure 9). For a person walking at an average speed of $5 \mathrm{~km} / \mathrm{h}$, a $1 \mathrm{~s}$ on $-4 \mathrm{~s}$ off rhythm would lead to a frequency of one vibration every $6.94 \mathrm{~m}$. If heading error is $15^{\circ}$ (the mean absolute error across the seven requested directions $0^{\circ}$ excluded - was $15.41^{\circ}$ for the long tactile mode), the distance error to the target would be $181 \mathrm{~cm}$. If the delay between two vibrations is reduced to $1 \mathrm{~s}$ ( $1 \mathrm{~s}$ on $-1 \mathrm{~s}$ off rhythm), the same heading error would lead to a distance error of $73 \mathrm{~cm}$.

Whether these amounts of error are acceptable or not depends on the task. If the vibration indicates a target of sufficient size that is visible to the user (e.g., a building, a path fairly apart from other ways), large errors may not prevent this user from reaching his or her goal. On the other hand, if the user cannot see the target because of vision conditions (e.g., darkness, smoke, fog), because of visual impairment, or because the target is hidden by other elements in the environment, greater accuracy is needed. The same principle applies if the task cannot allow deviations from the shortest route (e.g., if time is crucial to achieving the goal) or if it necessitates high accuracy (e.g., to grasp an object, to avoid obstacles). Our results show that a heading error of about $10^{\circ}$ can be expected from the short tactile mode (the mean absolute error across the seven requested directions $-0^{\circ}$ excluded - was $10.05^{\circ}$ for the short tactile mode). Given that this guidance mode allows continuous updating of spatial information, it can be expected that this heading error will not produce an increase in distance error with locomotion as for the long tactile mode (Figure 9). Heading error could be continually reduced, resulting in virtually no gap between the route followed by the user and the one indicated by spatial information. This prediction should be tested with an ecological navigation task (see below for the technological implications of use in the field).

A secondary but interesting result was that heading accuracy (measured by constant, absolute or variable errors) did not differ between the long tactile mode and the verbal mode, showing that a single vibratory burst delivered before movement, although less effective than the short tactile mode, is as effective as spatial language. This result can be related to the absence of difference in heading accuracy that was found for the comparison of 3-D sound (provided before body movement) to spatial language (expressed into clock position, e.g., "3 o'clock") with a task involving direct or indirect walking to the target location (Loomis et al., 2002). The present study offers preliminary insight related to extending the question of functional equivalence across modalities (e.g., Avraamides, Loomis, Klatzky, \& Golledge, 2004; Klatzky et al., 2002, 2003; Loomis et al., 2002; Loomis, Klatzky, \& Giudice, 2013) to the tactile modality that deserves to be specifically addressed in future research with more complex tasks implying multiple targets or indirect path integration (e.g., Klatzky et al., 2003; Loomis et al., 2002).

\section{Heading With No Visual Information}

The darkness condition prohibited access to environmental information that directly specifies changing orientations relative to objects fixed in the surroundings (Rieser, 1989). We observed that heading accuracy was impaired by such a deprivation when 


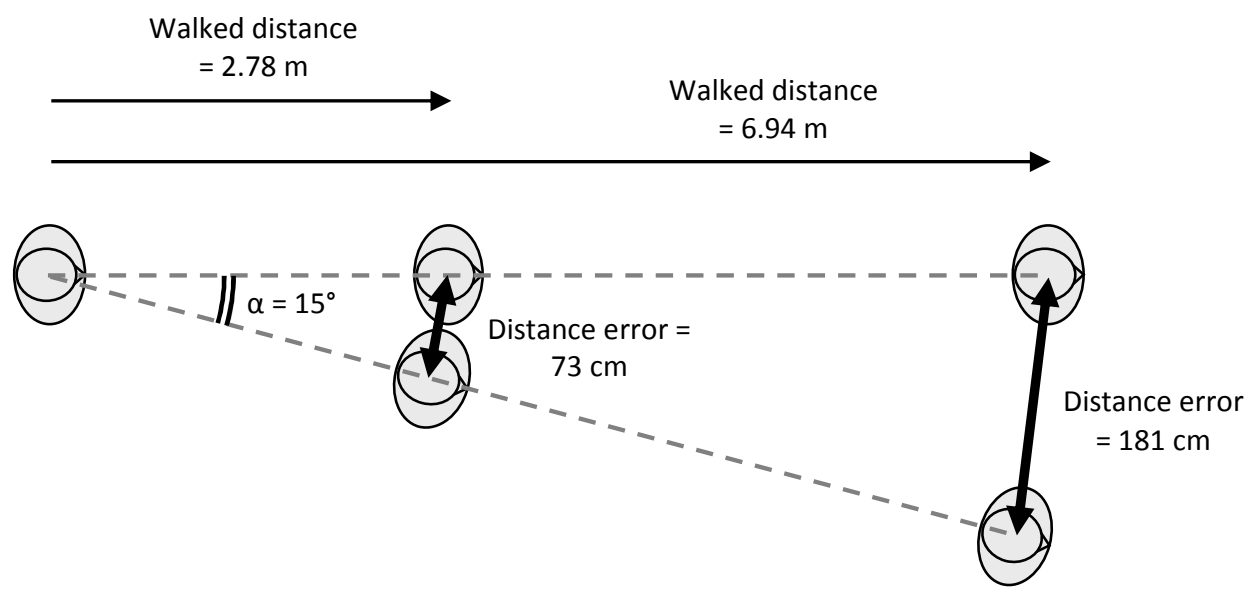

Figure 9. Consequence of heading error in units of distance. The error in meters (distance error) produced by the heading error $(\alpha)$ depends on the distance covered between two presentations of spatial information (walked distance). See the text for details.

spatial information was delivered through spatial language (verbal mode), but not through tactile stimulation (both tactile modes, regardless of vibration rhythm). Interpreting this finding is not straightforward, and requires having a closer look at the main features of the perceptual information available in the different conditions of the present study.

From Table 2, which summarizes these features (note that kinesthetic and vestibular inputs are not presented because they were equally present in every experimental condition), we can see that a major difference between tactile stimulation and spatial language is that, when presented in the form of a waist belt, tactile information is intrinsically spatialized, that is, the location of the vibration on the skin indicates a position within the environmental space. This position may have acted as an anchoring point in the environment that might have helped the users in the absence of vision. On the other hand, spatial language offers no direct reference position to relate to the environment (e.g., Avraamides et al., 2004) which might explain why participants partly relied on vision to get information about their orientation within the environment, and why they experienced more difficulty orienting themselves with the verbal mode when no visual information was available. It should be noted that even if the long tactile mode did not provide concurrent information about the relation between the user and the environment, heading performance was not impaired in the darkness condition for this guidance mode, suggesting that participants did not exploit this information for the heading task when it was available visually. Again, it can be suggested that the spatialized nature of tactile information played a critical role in how the users controlled their movements to face the requested directions.

In any case, these results reveal a great benefit of tactile guidance for navigation in poor visual conditions, which is one of the main foreseen applications of mobility devices. This finding is also promising for visually impaired people, but further research involving blind participants would be needed to assess the effectiveness of tactile guidance for this population.

\section{Direction of Heading Error: No Bias Away From or Toward the Body Midline}

In the introduction, we described the diverging bias in the localization of vibrations reported by Cholewiak et al. (2004) and van Erp $(2005,2008)$, with tasks involving stationary responses. Cholewiak et al. (2004) observed a bias away from the midsagittal plane (i.e., body midline), while van Erp (2005, 2008) observed a bias toward the midsagittal plane. Based on his results, van Erp (2005) proposed applying a torso-related transfer function (TRTF) to tactile guidance displays by shifting the location of the vibrators away from the body midline in order to map the external directions to specific locations on the skin.

The diverging results obtained by Cholewiak et al. (2004) and van Erp $(2005,2008)$ do not match our findings. With wholebody turning responses, we observed no bias toward or away

Table 2.

Main features of available perceptual information.

\begin{tabular}{|c|c|c|c|c|}
\hline & \multirow[b]{2}{*}{ Modality } & \multicolumn{2}{|c|}{ Information content } & \multirow[b]{2}{*}{$\begin{array}{c}\text { Concurrence with } \\
\text { movement }\end{array}$} \\
\hline & & Requested direction & $\begin{array}{l}\text { User-Environment } \\
\text { interaction }\end{array}$ & \\
\hline Vision & Visual & No & Yes & Yes (continuous) \\
\hline Short tactile & Vibrotactile & Yes, spatialized & Yes & Yes (every $400 \mathrm{~ms}$ ) \\
\hline Long tactile & Vibrotactile & Yes, spatialized & No & No \\
\hline Verbal & Spatial language & Yes, not spatialized & No & No \\
\hline
\end{tabular}


from the body midline, but a systematic tendency to overshoot the requested direction, whether the requested direction was on the frontal side or on the dorsal side of the body (Figure 5). Only $180^{\circ}$ (and obviously $0^{\circ}$, for which no movement was required) were exceptions, with a positive but small mean constant error (less than $5^{\circ}$, Figure 4A). Note that this overshooting tendency was not specific to tactile guidance: it was observed in similar amounts for the verbal mode and the long tactile mode, and was less pronounced (but still present) for the short tactile mode.

As a result, when vibrotactile waist belts are designed for spatial guidance applications with the location of the vibration indicating the direction to turn to, we argue that applying the torso-related transfer function proposed by van Erp (2005) may increase heading errors for the vibrations located on the frontal side of the torso. Nevertheless, it would be interesting to investigate whether heading errors could be reduced by a transfer function of the same kind which would compensate for overshoots and not for a bias toward the body midline. Because the magnitude of bias is dependent on tactile temporal parameters, the amount of correction that should be applied to vibrators' location in such a case would have to be defined according to the stimulation rhythm and whether the stimulation is updated or not during body rotation.

\section{Perception-Action Coupling in Human-Machine Interfaces}

The present research gives relevant directions for the design of tactile navigation devices. As a few other researchers in the domain of tactile displays have previously argued (Cáncar, Díaz, Barrientos, Travieso, \& Jacobs, 2013; Díaz, Barrientos, Jacobs, \& Travieso, 2012; Nagel et al., 2005), we believe that coupling the device stimulation with the user's action is highly beneficial. Even if this coupling is not as continuous as in unenhanced perception, it allows the user to actively search for goal-relevant information from the circular causality between perception and action (e.g., Gibson, 1966). From a different but connected theoretical approach, one could say that the user has access to sensorimotor contingencies, that is, the rules governing the sensory changes produced by motor actions (O'Regan \& Noë, 2001).

This recommendation yields two implications. First, to ensure that updated tactile stimulation is available to the user during movement, the choice of vibration rhythm must take into account the extent of motion and the speed with which body rotation is achieved. If vibration rhythm is set too low with respect to these factors, the user will either not receive reciprocal information during movement (and therefore lose the benefits of informationmovement coupling regarding heading accuracy) or have to slow down the movement (and therefore lose the benefits of tactile information regarding movement speed). Data from the present study showed that the velocity of body rotation increased with the extent of movement, with minimal values for requested directions of $45^{\circ}$ and maximal values for requested directions of $180^{\circ}$. The mean values were similar across guidance conditions: from $28.52^{\circ} . \mathrm{s}^{-1}$ to $70.87^{\circ} . \mathrm{s}^{-1}$ for the verbal condition, from $33.24^{\circ} . \mathrm{s}^{-1}$ to $80.60^{\circ} . \mathrm{s}^{-1}$ for the long tactile mode, and from $34.22^{\circ} . \mathrm{s}^{-1}$ to $71.05^{\circ} . \mathrm{s}^{-1}$ for the short tactile mode. The speed values observed for the short tactile mode $(200 \mathrm{~ms}$ on $-200 \mathrm{~ms}$ off rhythm) indicate that the users received, on average, from 3.25 vibrations for requested directions of $\pm 45^{\circ}$ to 6.51 vibrations for requested directions of $180^{\circ}$.
The second implication of perception-action coupling is that the refresh rate of body position measures has to be sufficient. Most of the recent tactile devices designed to assist navigation are integrated with a global positioning system (GPS), a digital compass, a battery, and a microcomputer (e.g., Grierson et al., 2009; Tsukada \& Yasumura, 2004; van Erp et al., 2005; Zelek \& Holbein, 2008). The compass and GPS provide information about the user's location and heading to the microcomputer, which in turn trigger the activation of the vibrator corresponding to the direction to turn to. This combination of technologies perfectly suits the delivery of a tactile rhythm that allows the updating of directional information along with the user's movement. Nevertheless, special care in the update rate features must be taken to choose the compass and GPS models. For example, the $200 \mathrm{~ms}$ on $-200 \mathrm{~ms}$ off rhythm that we used in the present study implies a rate of three vibratory bursts per second, and then necessitates an update rate well above $3 \mathrm{~Hz}$ for data about the user's location and heading.

Finally, it is important to mention that the results from the present experiment cannot be generalized to all tactile guidance system. In accordance with guidelines for the design of vibrotactile devices (e.g., Jones \& Sarter, 2008), features relating to psychophysics such as stimulus frequency, duration, intensity, body site but also adaptation or masking phenomena (e.g., Geldard, 1960; Kaczmarek, Webster, Bach-y-Rita \& Tompkins, 1991) must be considered carefully. Therefore, the performance measures obtained in the present study are valid for the specific features we tested, such as temporal parameters, body site, distance between vibrators, and the size of vibrators, and changing one of these parameters may alter the pattern of results.

\section{Conclusion}

The present findings can be of great value for the design of tactile devices intended for users navigating in hostile environments, for visually impaired people, and for any context that would benefit from leaving the eyes, ears and hands free for other tasks. In fact, the rigorous quantification of heading performance conducted in this study confirms that tactile displays can be effective in assisting body orientation and reveal that they present great advantages compared to spatial language when tactile stimulation is reciprocally related to the user's movements. This conclusion applies to both objective measures of performance (heading accuracy and time of response) and to participants' preferences.

An interesting question for future research would be to assess the cognitive load related to tactile guidance, as was done for alternative modes of guidance such as virtual sound (Klatzky et al., 2006). Another interesting question would be to study how information about distance can be delivered through tactile stimulation. It may not be essential to continuously provide information about distance to guide the user to a point of interest, but if the stimulation indicates the location of an obstacle or the location of an object to grasp, the distance to the point of interest may be fundamental. Until now (Tsukada \& Yasumura, 2004; van Erp et al., 2005), distance has been coded through conventionally defined vibration rhythm, which did not prove to be effective. Another strategy could be to map tactile stimulation to optical flow structures known to be informative about depth and distance such as motion parallax, or more functional information for locomotion such as time-to-contact (Lee, 1974; Lee \& Lishman, 1977; Savelsbergh, 1993). 


\section{References}

Avraamides, M. N., Loomis, J. M., Klatzky, R. L., \& Golledge, R. G. (2004). Functional equivalence of spatial representations derived from vision and language: evidence from allocentric judgments. Journal of Experimental Psychology: Learning, Memory, and Cognition, 30, 801-814. doi:10.1037/0278-7393.30.4.804

Bach-y-Rita, P., Collins, C. C., Saunders, F., White, B., \& Scadden, L. (1969). Vision substitution by tactile image projection. Nature, 221, 963-964. doi:10.1038/221963a0

Barralon, P., Dumont, G., Schwarz, S. K. W., Magruder, W., \& Ansermino, J. M. (2009). Comparison between a dorsal and a belt tactile display prototype for decoding physiological events in the operating room. Journal of Clinical Monitoring and Computing, 23, 137-147. doi:10.1007/s10877-009-9175-y

Batschelet, E. (1981). Circular statistics in biology. New York: Academic Press.

Borg, E., Rönnberg, J., \& Neovius, L. (2001). Vibratory-coded directional analysis: Evaluation of a three-microphone/four-vibrator DSP system. Journal of Rehabilitation Research and Development, 38, 257-263.

Brouwer, A-M., \& van Erp, J. B. F. (2010). A tactile P300 braincomputer interface. Frontiers in Neuroscience, 4, 1-11. doi:10.3389/fnins.2010.00019

Cáncar, L., Díaz, A., Barrientos, A., Travieso, D., \& Jacobs, D. M. (2013). Tactile-sight: A sensory substitution device based on distance-related vibrotactile flow. International Journal of Advanced Robotic Systems, 10, 1-11. doi: 10.5772/56235.

Castle, H., \& Dobbins, T. (2004). Tactile display technology: A brief overview of its benefits over visual and audio displays. Ingenia, Technology and Innovation, 20, p. 31-34

Cholewiak, R. W. (1984). Vibrotactile pattern recognition and discrimination at several body sites. Perception \& Psychophysics, 35, 503-514. doi:10.3758/BF03205946

Cholewiak, R. W., Brill, C. J., \& Schwab, A. (2004). Vibrotactile localization on the abdomen: Effects of place and space. Perception \& Psychophysics, 66, 970-987. doi:10.3758/BF03194989

de Vries, S. C., van Erp, J. B. F., \& Kiefer, R. J. (2009). Direction coding using a tactile chair. Applied Ergonomics, 40, 477-484 doi:10.1016/j.apergo.2008.09.008

Díaz, A., Barrientos, A., Jacobs, D. M., Travieso, D. (2012). Actioncontingent vibrotactile flow facilitates the detection of ground level obstacles with a partly virtual sensory substitution device. Human Movement Science, 31, 1571-1584. doi:10.1016/j.humov.2012.05.006.

Elliott, L. R. , Redden, E., Pettitt, R. , Carstens, C., van Erp, J. B. F., \& Duistermaat M. (2006). Tactile Guidance for Land Navigation. ARL-TR-3814, Army Research Laboratory, Aberdeen Proving Ground.

Elliott, L. R., van Erp, J. B. F., Redden, E. S., \& Duistermaat, M (2010). Field-based validation of a tactile navigation device. IEEE Transactions on Haptics, 3, 78-87. doi:10.1109/TOH.2010.3

Ferscha, A., Emsenhuber, B., Riener, A., Holzmann, C., Hechinger, M., Hochreiter, D., Franz, M., Zeidler, A., dos Santos Rocha, M., \& Klein, C. (2008). Vibro-tactile space-awareness. Adjunct Proceedings of the 10th International Conference on Ubiquitous Computing (UBICOMP'08), Seoul, South Korea, Video paper.

Geldard, F. A. (1957). Adventures in tactile literacy. American Psychologist, 12, 115-124. doi: $10.1037 / \mathrm{h} 0040416$

Geldard, F. A. (1960). Some neglected possibilities of communication. Science, 131, 1583-1588. doi:10.1126/science.131.3413.1583

Ghiani, G., Leporini, B., \& Paternò, F. (2009). Vibrotactile feedback to aid blind users of mobile guides. Journal of Visual Languages and Computing, 20, 305-317. doi:10.1016/j.jvlc.2009.07.004

Gibson, J. J. (1966). The Senses Considered as Perceptual Systems. Boston: Houghton Mifflin.

Gibson, J. J. (1979). The Ecological Approach to Visual Perception. Boston: Houghton Mifflin.
Grierson, L. E. M., Zelek, J., \& Carnahan, H. (2009). The application of a tactile way-finding belt to facilitate navigation in older persons. Aging International, 34, 203-215. doi:10.1007/s12126-009-9039-2

Grierson, L. E. M., Zelek, J., Lam, I., Black, S. E., \& Carnahan, H. (2011). Application of a tactile way-finding device to facilitate navigation in persons with dementia. Assistive Technology, 23, 108115. doi:10.1080/10400435.2011.567375

Haber, L., Haber, R. N., Penningroth, S., Novak, K., \& Radgowski, H. (1993). Comparison of nine methods of indicating the direction to objects: Data from blind adults. Perception, 22, 35-47. doi:10.1068/p220035

Ho, C., \& Spence, C. (2007). Head orientation biases tactile localization. Brain Research, 1144, 136-141. doi:10.1016/j.brainres.2007.01.091

Jansson, G. (1983). Tactile guidance of movement. International Journal of Neuroscience, $19, \quad 37-46$ doi: $10.3109 / 00207458309148644$

Jones, L. A., \& Sarter, N. B. (2008). Tactile displays: Guidance for their design and application. Human Factors, 50, 90-111. doi:10.1518/001872008X250638

Kaczmarek, K. A., Webster, J. G., Bach-y-Rita, P., \& Tompkins, W. J. (1991). Electrotactile and vibrotactile displays for sensory substitution systems. IEEE Transactions on Biomedical Engineering, 38, 1-16. doi:10.1109/10.68204

Kirman, J. H. (1974). Tactile apparent movement: The effects of interstimulus onset interval and stimulus duration. Perception \& Psychophysics, 15, 1-6. doi:10.3758/BF03205819

Klatzky, R. L., Lippa, Y., Loomis, J. M., \& Golledge, R. G. (2002). Learning directions of objects specified by vision, spatial audition, or auditory spatial language. Learning \& Memory, 9, 364-367. doi:10.1101/lm.51702

Klatzky, R. L., Lippa, Y., Loomis, J. M., \& Golledge, R. G. (2003). Encoding, learning, and spatial updating of multiple object locations specified by 3-D sound, spatial language, and vision. Experimental Brain Research, 149, 48-61. doi:10.1007/s00221002-1334-Z

Klatzky, R. L., Marston, J. R., Giudice, N. A., Golledge, R. G., \& Loomis, J. M. (2006). Cognitive Load of Navigating without Vision when Guided by Virtual Sound versus Spatial Language. Journal of Experimental Psychology: Applied, 12, 223-233. doi:10.1037/1076898X.12.4.223

Lee, D. N. (1974). Visual information during locomotion. In: R. B. MacLeod \& H. L. Pick (Eds), Perception: Essays in honor of James J. Gibson. Ithaca, NY: Cornell University Press. doi:10.1002/sce. 3730600123

Lee, D. N., \& Lishman, R. (1977). Visual control of locomotion. Scandinavian Journal of Psychology, 18, 224-230. doi:10.1111/j.1467-9450.1977.tb00281.x

Lindeman, R. W., Sibert, J. L., Mendez-Mendez, E., Patil, S., \& Phifer, D. (2005). Effectiveness of directional vibrotactile cuing on a building-clearing task. Proceedings of the SIGCHI Conference on Human Factors in Computing Systems (CHI '05). ACM, New York, NY, USA, 271-280

Loomis, J. M., \& Beall, A. C. (2004). Model-Based Control of Perception/Action. In L. M. Vaina, S. A. Beardsley, \& S. K. Rushton (Éd.), Optic Flow and Beyond (p. 421-441). Springer Netherlands. Retreived from http://link.springer.com/chapter/10.1007/978-1-4020-2092-6_19

Loomis, J. M., Da Silva, J. A., Fujita, N., \& Fukusima, S. S. (1992). Visual space perception and visually directed action. Journal of Experimental Psychology: Human Perception and Performance, 18, 906-921. doi:10.1037/0096-1523.18.4.906

Loomis, J. M., Golledge, R. G., \& Klatzky, R. L. (1998). Navigation system for the blind: Auditory display modes and guidance. Presence: Teleoperators and Virtual Environments, 7, 193-203. doi:10.1162/105474698565677

Loomis, J. M., Golledge, R. G., Klatzky, R. L., \& Marston, J. R. (2007). Assisting wayfinding in visually impaired travelers. In G. Allen (Ed.), Applied spatial cognition: From research to cognitive 
technology (pp. 179-202). Mahwah, N. J.: Lawrence Erlbaum Associates.

Loomis, J. M., Golledge, R. G., Klatzky, R. L., Speigle, J. M., \& Tietz, J. (1994). Personal guidance system for the visually impaired. Proceedings of the First Annual ACM/SIGGAPH Conference on Assistive Technologies, pp. 85-91. New York: Association for Computing Machinery. doi:10.1145/191028.191051

Loomis, J. M., Klatzky, R. L., \& Giudice, N. A. (2013). Representing 3D space in working memory: Spatial images from vision, touch, hearing, and language. In S. Lacey \& R. Lawson (Eds.), Multisensory Imagery (pp. 131-156). New York: Springer. Retreived from http://link.springer.com/chapter/10.1007/978-14614-5879-1_8

Loomis, J. M., Marston, J. R., Golledge, R. G., \& Klatzky, R. L. (2005). Personal guidance system for people with visual impairment: A comparison of spatial displays for route guidance. Journal of Visual Impairment \& Blindness, 99, 219-232. Retreived from http://www.afb.org/afbpress/pubjvib.asp?DocID=JVIB990404

Loomis, J. M., Lippa, Y., Klatzky, R. L., \& Golledge, R. G. (2002). Spatial updating of locations specified by 3-d sound and spatial language. Journal of Experimental Psychology: Learning, Memory, and Cognition, 28, 335-345. doi:10.1037/0278-7393.28.2.335

Mardia, K. V., \& Jupp, P. E. (2000). Directional statistics. Chichester, England: Wiley. doi:10.1002/9780470316979

Marston, J. R., Loomis, J. M., Klatzky, R. L., \& Golledge, R. G. (2007). Nonvisual route following with guidance from a simple haptic or auditory display. Journal of Visual Impairment \& Blindness, 101, 203-211.

Montello, D. R., Richardson, A. E., Hegarty, M., \& Provenza, M. (1999). A comparison of methods for estimating directions in egocentric space. Perception, 28, 981-1000. doi:10.1068/p2940

Nagel, S. K., Carl, C., Kringe, T., Märtin, R., \& König, P. (2005). Beyond sensory substitution - learning the sixth sense. Journal of Neural Engineering, 2, R13-R26. doi:10.1088/1741-2560/2/4/R02

O'Regan, J. K., \& Noë, A. (2001). A sensorimotor account of vision and visual consciousness. Behavioral and Brain Sciences, 24, 9391031. doi:10.1017/S0140525X01000115

Philbeck, J., Sargent, J., Arthur, J., \& Dopkins, S. (2008). Large manual pointing errors, but accurate verbal reports, for indications of target azimuth. Perception, 37, 511-534. doi:10.1068/p5839

Pielot, M., Poppinga, B., Heuten, W., \& Boll, S. (2011). A tactile compass for eyes-free pedestrian navigation. Proceedings of the 13th IFIP TC 13 international conference on Human-computer interaction, INTERACT'11, vol. 2, 640-656. doi:10.1007/978-3642-23771-3_47

Rieser, J. J. (1989). Access to knowledge of spatial structure at novel points of observation. Journal of Experimental Psychology: Learning, Memory, and Cognition, 15, 1157-1165. doi:10.1037/0278-7393.15.6.1157

Savelsbergh, G. J. P. (1993). Time-to-contact judgements based on haptic information. In: S. Valenti (Ed.), Proceedings of the VIIth International Conference on Event Perception and Action. Hillsdale: Erlbaum.

Srikulwong, M., \& O'Neill, E. (2010). A direct experimental comparison of back array and waist-belt tactile interfaces for indicating direction. Proceedings of the Workshop on Multimodal location based techniques for extreme navigation, Pervasive 2010, Helsinki, Finland.

Tan, H. Z., Gray, R., Young, J. J., \& Traylor, R. (2003). A Haptic Back Display for Attentional and Directional Cueing. Haptics-e: The Electronic Journal of Haptics Research, 3. Retreived from http://www.haptics-e.org.

Thomson, J. A. (1983). Is continuous visual monitoring necessary in visually guided locomotion? Journal of Experimental Psychology: Human Perception and Performance, 9, 427-443. doi:10.1037/0096-1523.9.3.427

Tsukada, K., \& Yasumura, M. (2004). ActiveBelt: Belt-type Wearable Tactile Display for Directional Navigation. In: N. Davies, E. D. Mynatt, \& I. Siio (Eds.), UbiComp 2004: Ubiquitous Computing, LNCS, Vol. 3205 (pp. 384-399). Berlin, Germany: Springer-Verlag. doi:10.1007/978-3-540-30119-6_23

Warren, W. H. (1998). Visually controlled locomotion: 40 years later. $\begin{array}{llll}\text { Ecological } & \text { Psychology, } & 10, & 177-219\end{array}$ doi:10.1080/10407413.1998.9652682

Warren, W. H. (2006). The dynamics of perception and action. Psychological review, 113, 358-389. doi:10.1037/0033295X.113.2.358

van Erp, J. B. F. (2005). Presenting directions with a vibrotactile torso $\begin{array}{lll}\text { display. } & \text { Ergonomics, } & \text { 30, }\end{array}$ doi:10.1080/0014013042000327670

van Erp, J. B. F. (2008). Absolute localization of vibrotactile stimuli on the torso. Perception \& Psychophysics, 70, 1016-1023. doi: 10.3758/PP.70.6.1016

van Erp, J. B. F., Saturday, I., \& Jansen, C. (2006). Application of tactile displays in sports: where to, how and when to move, Proceedings of EuroHaptics 2006, Paris, France. Retreived from http://lsc.univ-evry.fr/ eurohaptics/upload/cd/papers/f1.pdf

van Erp, J. B. F., \& Self, B. P. (2008). Tactile Displays for Orientation, Navigation and Communication in Air, Sea, and Land Environments (RTO-TR-HFM-122). Research and Technology Organisation and North Atlantic Treaty Organisation: Neuilly-surSeine Cedex, France, pp 1-1-1-18. Retreived from http://ftp.rta.nato.int/public/PubFullText/RTO/TR/RTO-TR-HFM122/\$TR-HFM-122-ES.pdf

van Erp, J. B. F., Spapé, M. M. A., \& Van Veen, H. A. H. C. (2003). Waypoint navigation on land with the TNO Personal Tactile Navigator (PeTaNa) [Waypoint navigatie op het land met de TNO Personal Tactile Navigator (PeTaNa)] (TNO report: TM-03-A045). Soesterberg, NL: TNO Human Factors.

van Erp, J. B. F., \& van Veen, H. A. H. C. (2004). Vibrotactile invehicle navigation system. Transportation Research, Part F 7, 247256. doi:10.1016/j.trf.2004.09.003

van Erp, J. B. F., van Veen, H. A. H. C., Jansen, C., \& Dobbins, T. (2005). Waypoint navigation with a vibrotactile waist belt. ACM Transactions on Applied Perception, 2, 106-117. doi:10.1145/1060581.1060585

van Erp, J. B. F., \& Verschoor, M. H. (2004). Cross-modal visual and vibro-tactile tracking. Applied Ergonomics, 35, 105-112. doi:10.1016/j.apergo.2003.12.004

Zelek, J. S., \& Holbein, M. (2008, May 22). Publication Number: US 2008/0120029. United States Patent Application, 11/707, 031. 